\title{
Mating systems and predictors of relative reproductive success in a cutthroat trout subspecies of conservation concern
}

\author{
John Hargrove ${ }^{1}$, Jesse McCane ${ }^{1}$, Curtis Roth $^{2}$, Brett High $^{2}$, and Matthew Campbell ${ }^{2}$ \\ ${ }^{1}$ Pacific States Marine Fisheries Commission \\ ${ }^{2}$ Idaho Department of Fish and Game
}

December 9, 2020

\begin{abstract}
Mating systems and patterns in reproductive success of fishes play an important role in ecology and evolution. While information on the reproductive ecology of many anadromous salmonids (Oncorhynchus spp.) is well-detailed, there is less information for non-anadromous species including the Yellowstone Cutthroat Trout (O. clarkii bouvieri), a species of recreational angling importance and conservation concern. Here, we used data from a parentage-based tagging study to describe the mating system of Yellowstone Cutthroat Trout from a spawning tributary of the South Fork Snake River, Idaho, and identify predictors of relative reproductive success. We detected evidence of monogamy, polygyny, and polyandry and showed that reproductive success was best explained by arrival time at the spawning ground and total length. Specifically, the largest adults arrived earliest in the season and produced a disproportionate number of offspring. Lastly, we estimated the effective number of breeders $\left(N_{\mathrm{b}}\right)$ and effective population size $\left(N_{\mathrm{e}}\right)$ and showed that while $\mathrm{Nb}$ was lower than $\mathrm{Ne}$, both are sufficiently high to suggest Yellowstone Cutthroat Trout in Burns Creek represent a genetically stable and diverse population.
\end{abstract}

\section{INTRODUCTION}

Freshwater fishes display a diversity of mating systems and reproductive behaviors (DeWoody and Avise 2001), and knowledge of reproductive ecology and drivers of reproductive success are relevant to both conservation and management efforts. For example, effective population size $\left(N_{\text {e }}\right)$ measures the rate of genetic drift within a population (Charlesworth 2009), and reproductive characteristics such as family size, variance in reproductive success, and adult sex ratios directly influence $N_{\mathrm{e}}$. In particular, populations that display large variances in reproductive success, unequal family sizes, and heavily skewed sex ratios will have lower values of $N_{\mathrm{e}}$, experience greater losses in genetic diversity via genetic drift, and be at an elevated risk of extirpation (Frankham 2005). In addition to potentially impacting persistence, mating systems and knowledge thereof may be directly applicable to hatchery supplementation efforts whereby managers may wish to emulate patterns observed in the wild.

Pacific salmonids (Oncorhynchus spp.) are of profound recreational, ecological, and economic importance throughout their range (Quinn 2018). Rates of imperilment among salmon are high (Gustafson et al. 2007), and efforts to assess the viability of distinct population segments include quantifying levels of genetic diversity (McElhaney et al. 2000). Given the direct link between reproductive characteristics and levels of genetic diversity, knowledge of mating systems is directly relevant to conservation planning and management. The mating systems and predictors of reproductive success of many salmonid species have been described in detail (Brook Trout, Salvelinus fontinalis : Kanno et al. 2011; Steelhead, Oncorhynchus mykiss : Seamons et al. 2004a; McMillan et al. 2007; Atlantic salmon, Salmo salar : Garant et al. 2001); however, there is no such data for species such as Yellowstone Cutthroat Trout (Oncorhynchus clarkii bouvieri).

Yellowstone Cutthroat Trout are an iconic species of the western United States, and are one of three sub- 
species of Cutthroat Trout native to Idaho. Yellowstone Cutthroat Trout are thought to occupy less than half of their historical habitats rangewide (May et al. 2003; Meyer et al. 2006), and are considered to be a high-priority species with a standalone management and conservation plan (IDFG 2007). Primary factors associated with declines include hybridization with non-native Rainbow Trout (O. mykiss), competition with invasive species (e.g., Brook Trout), overharvest, water diversion, and habitat alterations (Varley and Gresswell 1988; Behnke 1992; Kruse et al. 2000). Despite a range contraction relative to historical records, the abundance and size structure of Yellowstone Cutthroat Trout in Idaho have remained relatively stable over the last 20 years (Meyer et al. 2003; Meyer et al. 2014). Although Yellowstone Cutthroat Trout have been extensively studied, we found no published literature describing their mating systems. Recent efforts that have sought to understand how angling impacts the reproductive success of Yellowstone Cutthroat Trout (Roth et al. 2018), and the associated data sets have afforded the opportunity to use extensive field sampling of parents and progeny to describe mating systems and patterns of reproductive success.

This study used an existing data set to describe the genetic mating system of Yellowstone Cutthroat Trout. Specifically, we were interested in identifying the number of mates and number of offspring produced by males and females, testing for evidence of inbreeding avoidance, and exploring the effect that arrival timing at spawning grounds and total length had on offspring production. To accomplish these goals, we made use of data collected by Roth et al. (2018) in which prespawn adults were sampled at a weir as they entered a spawning tributary as well as their outmigrating juvenile offspring as they left the system. All sampled adults and juveniles were genotyped using a panel of single nucleotide polymorphisms (SNPs), and a combination of parentage analysis and sibship estimation were used to document the mating system (e.g., monogamy, polygamy, etc.) and estimate the reproductive success of sampled parents. Additionally, we used generalized linear models to estimate the relative predictive importance of arrival date and total length on offspring production. We also tested for the presence of inbreeding avoidance among adults via comparisons of simulated and observed levels of genetic relatedness for parents that did and did not contribute to reproduction. Lastly, we estimated metrics of the effective number of breeders $\left(N_{\mathrm{b}}\right)$ and effective population size $\left(N_{\mathrm{e}}\right)$ via sibship analysis applied to collections of juveniles and parents respectively. Combined, we present the first detailed description of the genetic mating systems of Yellowstone Cutthroat Trout and drivers of reproductive success.

\section{METHODS}

\section{Sample collection}

The samples used in the current study were a subset of those described in Roth et al. (2018) which assessed the effects of air exposure and angling on short- and long-term survival as well as progeny production of adult Yellowstone Cutthroat Trout. Results identified that air exposure had no statistically significant effect on the proportion of fish that successfully spawned and that neither angling nor air exposure significantly affected progeny production (Roth et al. 2018). Given the lack of observed impacts of air exposure and angling on reproductive contributions and reproductive success, we concluded that data on mating systems for Yellowstone Cutthroat Trout derived from the samples of Roth et al. (2018) would be reflective of patterns in naturally occurring populations.

A detailed description of all sampling methods can be found in Roth et al. (2018). Briefly, sampling was conducted on Burns Creek, Idaho (Figure 1 ), a tributary to the South Fork Snake River, from May to October 2016. A large portion of Yellowstone Cutthroat Trout in this system display a fluvial life history strategy with adults moving from the mainstem of the South Fork Snake River into tributary systems to spawn (Thurow et al. 1988). Spawning typically begins in late May and continues into July. Fry in Burns Creek emerge between mid-July and September and out-migrate to the mainstem river as age-0 fish (Moore and Schill 1984; Thurow et al. 1988).

Adult Yellowstone Cutthroat Trout were sampled from May through July 2016 at an adult weir operated on Burns Creek, $0.9 \mathrm{~km}$ upstream of the creek mouth. Fish migrating upstream enter a fish trap which is located at the top of a fish ladder which is utilized to reach upstream habitats from the weir. The trap is 
operated annually by the IDFG with the purpose of removing straying Rainbow Trout and hybrids. The total length was recorded for each adult. A genetic fin clip was taken from each migrating adult and stored on Whatman 3MM chromatography paper (Thermo Fisher Scientific, Inc., Pittsburgh, Pennsylvania). The phenotypic sex of each adult was identified in the field and confirmed using a genetic assay with accuracy (e.g., 99\%; Schill et al. 2016).

Out-migrating age-0 Yellowstone Cutthroat Trout were collected later the same year using a combination of trapping and electrofishing methods. Fry were collected using a modified picket weir approximately $25 \mathrm{~m}$ downstream of the adult weir (described above) as well as with one Kray-Meekin trap placed in the thalweg downstream of the weir. Trapping occurred continuously between July and October in 2016. Additionally, single-pass backpack electrofishing was used to supplement fry collection and was performed over two $2 \mathrm{~d}$ periods in September and October. Backpack electrofishing was performed from the IDFG picket weir upstream for $4 \mathrm{~km}$. A subset of fry collected via traps and electrofishing were randomly sampled for genetic tissue. We assumed that the cumulative fry sampling was an accurate representation of total production/outmigration and made every effort to minimize bias that may have arisen due to sampling and subsampling.

\section{Genetic analysis}

The nonlethal genetic tagging method known as parentage-based tagging (PBT) was used to identify parentpair offspring relationships among sets of adult and offspring samples based on patterns in Mendelian inheritance (Steele et al. 2013; 2019). Results from PBT were then used to characterize mating systems and reproductive success among Yellowstone Cutthroat Trout.

Genomic DNA was extracted from fin clips using the nexttec Genomic DNA Isolation Kit (XpressBio, Thurmont, Maryland) following manufacturer's protocol. Samples were screened with a panel of 134 single nucleotide polymorphic (SNP) loci which included a sex-linked marker (2017SDYCUT ) used to identify genetic sex of each fish (see Roth et al. 2018 for sex-linked primer details). Genetic sex data was used to verify that parentage assignments were attributed to a male and female combination. Primer sequences for all SNPs are available from the authors upon request. Genotyping of SNPs was performed following the genotyping-in-thousands protocol described by Campbell et al. (2015). We screened all genotypes for duplicates and completeness; only unique genotypes that were [?]50\% complete (minimum of 66 loci) were retained for analyses. Two forms of parentage error, Type I and II error, were quantified by Roth et al. (2018) to assess the reliability of parentage assignments for this data set. Type I error measures the rate that untrue parent pairs were assigned as a true parent, and Type II error refers to the number of offspring for which a true parent pair was present but not assigned. Type I error was estimated using two separate methods and was determined to be 0.000 and 0.001 . Type II error was estimated to be 0.001 .

Parentage-based tagging was applied by Roth et al. (2018) to identify parent pair-offspring relationships. Specifically, adults were exhaustively sampled during their migration to spawning grounds and SNP genotype profiles were created for each adult. This approach effectively genetically tagged all offspring that would be the byproduct of matings among sampled adults. Parentage assignments in trios (both parents and one offspring) were estimated using the likelihood approach implemented within SNPPIT (Anderson and Garza 2005; Anderson 2010) assuming a per-allele genotyping error rate of $0.5 \%$. The confidence of assignments was assessed using the logarithm of odds (LOD) score generated by SNPPIT. The LOD score represents the natural logarithm of the likelihood of the parental trio hypothesis divided by the likelihood of the nonparental hypothesis for a trio. Only parentage assignments with a LOD score [?] 18 were retained as previous analysis has identified this threshold minimized false positive and false negative assignments (Roth et al. 2018).

\section{Mating systems and relative reproductive success inferred via PBT}

Outputs from parentage analysis were used to generate individual profiles for each adult which included the number of offspring produced, the number of unique mates, and the number of offspring produced per mating. These data were then used to describe the mating system by looking for evidence of monogamy (one male mates with one female or vice versa), polygyny (one male mates with multiple females), or polyandry (one 
female mates with multiple males). Because Roth et al. (2018) did not quantify total offspring production and only a subset of offspring were analyzed for genetic analysis, we present measures of relative reproductive success among adults and relative production by different sexes. We quantified the correlation between the number of mates an adult acquired and the number of offspring produced using a Pearson's correlation coefficient.

Although we expected the incidence of false positive and false negative rates for parentage assignment to be low because we used stringent criteria to limit error (see above), we elected to use a complimentary analysis, sibship assignment (SA), to confirm PBT results. Briefly, we estimated full-sibling relationships among our juvenile collection using the sibship assignment approach implemented in the software program COLONY (Jones and Wang 2010), and compared the outputs from SA and parentage analysis. COLONY employs a full-likelihood approach to estimate sibship and has been shown to outperform other sibship reconstruction methods (Lepais et al. 2010). For comparison purposes, we determined the proportion of full sibling pairs that were identical based on the two estimation procedures. Additionally, we examined the number of fullsibling pairs that were detected by one program and not the other. Lastly, we report on the number of single children families detected via sibship assignment and parentage analysis.

Inbreeding avoidance among spawning adults

We tested for the presence of inbreeding avoidance among adult Yellowstone Cutthroat Trout to understand whether there are mechanisms that prevent breeding among related individuals. To do this, we first evaluated the accuracy of four different relatedness estimators (Queller \& Goodnight 1989; Li et al. 1993; Lynch \& Ritland 1999; and Wang 2002) based on correlation coefficients between observed and expected values. We employed the 'compareestimators' function in the relatedpackage in R (Pew et al. 2015; R Core Team 2020) which used observed allele frequencies within our focal population to simulate 1,000 individuals of known relatedness and selected the estimator with the highest correlation coefficient between known and estimated relationships. Next, we used outputs from parentage analysis to identify two subsets of the adult population, adults that were responsible for producing progeny and those that were not. We then calculated average within-group relatedness using the best-fit relatedness estimator for these two groups and compared against expected values using the 'grouprel' function within the related package. Briefly, expected values were generated by randomly shuffling individuals between groups (which were kept at a constant size), and then relatedness was calculating within these newly constructed groups. We performed a total of 100 simulations and $p$-values were estimated as the number of simulations out of the total number ran that were less than or equal to our observed value.

\section{Influence of migration timing and total length on relative reproductive success}

We explored the relationship between arrival date at the weir (i.e., a proxy for arrival date at the spawning ground) and the number of offspring produced to understand if specific arrival times were associated with higher relative reproductive success and if this varied by sex. We first summed the number of offspring that were assigned to a parent by the week they were sampled at the weir and then used a chi-square test to see if the total number of offspring produced per week was independent of sex. We summarized relative offspring production by week for this analysis only to ensure that sufficient observations were present across temporal periods to apply a chi-square test which was performed using R (R Core Team 2020). We assessed statistical significance using an alpha level of 0.05 .

Additionally, we were interested in understanding the relative predictive importance of arrival date and adult length on offspring production for Yellowstone Cutthroat Trout in Burns Creek. We modeled the effect of length (total length in $\mathrm{mm}$ ), date (Julian date of arrival at an instream weir directly downstream from spawning habitats), and an interaction term (length * date) to explain relative offspring production for males and females individually. To model the effects of total length and arrival timing we used generalized linear models with a negative binomial distribution to account for overdispersion in offspring production (Figure 2 ). Models were analyzed using the MASS package (Venables and Ripley 2002) in R (R Core Team 2020). We developed a suite of four a priori models including: 1) length (total length), 2) date (fitted 
as the quadratic function: arrival time ${ }^{*}$ arrival time $\left.{ }^{2}\right)$, 3) length + date, and 4) length * date. Each model was run separately for males and females. Models were compared using Akaike's information criterion corrected for small sample size (AIC $c$ ), and the top model was the one with the lowest AIC $c$ value (Burnham and Anderson 2002). Models that had an AIC $c$ score within 2.0 units of the best model's score were also considered as belonging to the set of top models.

Effective population size $\left(N_{\mathrm{e}}\right)$ and number of breeders $\left(N_{\mathrm{b}}\right)$

Effective population size can be estimated on multiple different scales, including over a generation $\left(N_{\text {e }}\right)$ or single reproductive cycle $\left(N_{\mathrm{b}}\right.$, effective number of breeders). Both metrics provide insights relevant to conservation and management. Namely, $N$ e quantifies the extent of drift and inbreeding experienced in a given population (Charlesworth 2009) and $N$ b estimates the number of effective breeders for a single reproductive season. A number of factors affect both $N_{\mathrm{e}}$ and $N_{\mathrm{b}}$, including operational sex ratio, variation in family size, inbreeding, and changes in population size; however these factors operate at different time scales (Waples 2002). We estimated both $N_{\mathrm{e}}$ and $N_{\mathrm{b}}$ for Yellowstone Cutthroat Trout, using the full likelihood method implemented in COLONY assuming random mating. Effective population size was calculated using the pooled parental population, which represented multiple different age classes. In contrast, we estimated $N$ b using only outmigrating juveniles, which would estimate the number of breeders contributing to the juvenile cohort.

\section{RESULTS}

\section{Sample collection 8 genetic analysis}

In 2016, a total of 1,520 upstream-migrating adult Yellowstone Cutthroat Trout and 2,925 fry were sampled for genetic tissue. Overall genotype success rates were very high, with $99.9 \%$ of adult samples $(1,518)$ and $99.7 \%$ of the juvenile samples $(2,917)$ successfully amplifying at $50 \%$ or more of the SNP marker panel. Searches for duplicate genotypes identified a total of 15 adult samples which were near exact matches ( $>95 \%$ similar) of another sample, which likely represented adults that passed above the weir, fell back, and were sampled again when they reascended the weir. Duplicate searches among offspring identified seven samples that were a duplicate of another. For both adults and offspring, only one genotype was retained from each pair of duplicates, whichever was the most complete (i.e., had the largest number of alleles called). Parentage analysis assigned 2,310 ( $78.7 \%$ of total number) of the fry samples to a parent-pair handled at the weir.

\section{Mating systems and reproductive success inferred via PBT}

Results from parentage-based tagging identified a total of 934 unique parent-pairs from a combinations of 373 male and 486 female Yellowstone Cutthroat trout. The number of mates per adult was right skewed, with no offspring contributions detected from $37.9 \%$ of females and $48.9 \%$ (Figure 2A ). Of the adults that were assigned at least one offspring, the most common number of mates per adult was one for both females $(27.7 \%)$ and males $(24.2 \%)$. Individual females mated with up to five different males, whereas males mated with up to 16 different females (Figure 2A ). The mean number of mates was 1.19 (SD: 1.25) for females and 1.28 (SD: 2.02) for males. The median number of mates was one for both males and females. Based on the reproductive profiles of individual adults we identified evidence of monogamy, polygyny, and polyandry.

Similar to the number of mates per adult, the distribution of relative reproductive success was right skewed. Among adults that contributed to reproduction, the most frequent number of offspring produced was one for both females (13.3\%) and males (11.9\%; Figure 2B ). The maximum number of offspring attributed to a female was 22 , whereas one male produced 57 offspring. The mean number of offspring produced per female was 2.95 (SD: 3.89 ) and 3.16 (SD: 6.22 ) for males.

A positive relationship was identified between the number of mates and the relative number of offspring produced (Figure 2C ). For both females and males, the average number of offspring per adult increased as a function of the number of mates acquired but the strength of this correlation differed by sex. Specifically, Pearson's correlation coefficient between the number of offspring produced and number of mates acquired was 0.77 and 0.89 for females and males, respectively. 
The same set of 3,862 full-sibling pairs were identified by both sibship assignment and parentage analysis. Seventeen full-sib pairs were detected by sibship assignment only, and 35 full-sib pairs were detected exclusively by parentage analysis. Discordance between methods (52 pairs differed of 3,914 total pairs) was 1.3\% indicating that both methods produced highly similar results. Both analyses identified 410 offspring that were 'only children' (i.e., had no full siblings) and an additional 33 'only children' were detected by sibship assignment and not PBT. Three 'only children' were detected by PBT but not sibship analysis.

\section{Inbreeding avoidance among spawning adults}

Among the four potential relatedness estimators considered, the Queller and Goodnight (1989) coefficient displayed the highest correlation between observed and expected values of relatedness (Pearson's correlation coefficient $=0.924)$. Observed relatedness among parents that were and were not assigned progeny was -0.00087 and 0.00015 , respectively (Figure 3 ). Expected levels of relatedness among individuals that were and were not assigned progeny were -0.00059 (SD: 0.00260) and -0.00068 (0.00157), respectively (Figure 3 ). Neither value of observed relatedness within a group was significantly different than expected values (assigned progeny: $\mathrm{p}<0.49$ and not assigned progeny: $\mathrm{p}<0.46$ ).

Influence of migration timing and total length on relative reproductive success

Mean arrival date at the weir for males was earlier than females (mean Julian date of arrival: females $=162$, males $=158 ;$ Figure 4A ). Total offspring production for males was highest for those that arrived midseason relative to early or late arriving males (Figure 4B ). We observed a greater variance in arrival date for males $\left(s^{2}=63.7\right)$ than females $\left(s^{2}=60.2\right)$. The total number of offspring produced per week peaked during the first week of June for both females and males, however, relative offspring production on a weekly basis (i.e., the sum of all offspring produced by adults that arrived within a given week) was significantly different as a function of $\operatorname{sex}\left(\chi^{2}=550.22, \mathrm{df}=6, p\right.$-value $\left.=2.2 \times 10^{-16}\right)$.

The relative number of offspring produced per adult increased as a function of size for both females and males (Figure 5 ), although the strength of this trend was greater for males. Additionally, we identified that the largest adult males arrived earlier than smaller males and were responsible for producing the greatest relative number of offspring (Figure 5 ). The best model which explained relative reproductive success was one that included both total length and date of arrival for both males and females (Table $\mathbf{1}$ ). The relative likelihood of the model which included length and date was 0.796 for females and 0.858 , both of which were much larger than the next best fit model ([?]AICc $>2$ ).

Effective population size $\left(N_{\mathrm{e}}\right)$ and number of breeders $\left(N_{\mathrm{b}}\right)$

The point estimate of $N$ e was $868(787-959,95 \% \mathrm{CI})$ and $N_{\mathrm{b}}$ was $576(513-650,95 \% \mathrm{CI})$. The ratio of $N$ b $/ N_{\text {e }}$ was 0.66 .

\section{DISCUSSION}

Using a parentage-based tagging approach we have provided the first description of the genetic mating system for Yellowstone Cutthroat Trout, a species of conservation concern and recreational angling importance. We documented multiple forms of mating among adults including monogamy, polygyny, and polyandry, and offspring production was found to be heavily right skewed with few adults producing many and most producing few or no offspring. The variance in relative reproductive success was higher among males than females as measured both by the number of mates acquired and number of offspring produced. We observed a positive correlation between the number of mates acquired and relative number of offspring produced; however, the strength of this correlation was lower for females than for males. On average, male adults had a greater number of mates and produced a higher number of offspring than their female counterparts. We failed to detect a signal of inbreeding avoidance, although the group of parents that produced progeny were on average slightly less related than adults that did not produce progeny. Both arrival date and total length were identified as significant predictors of relative reproductive success for both female and male Yellowstone Cutthroat Trout. Lastly, we identified that the effective number of breeders was lower than effective populations and these two parameter estimates had non-overlapping confidence intervals. Combined, 
the current study of Yellowstone Cutthroat Trout mating system helps to fill several gaps in knowledge regarding life history and these data may be useful moving forward for conservation and management efforts.

Social mating systems and spawning behaviors are well studied within salmonids (see Esteve 2005 for review); however, there remain taxa for which there is little or no information, including Cutthroat Trout. Several traits observed in our study of Yellowstone Cutthroat Trout were in line with patterns described for other members of the Salmonidae family. For example, we found evidence of both polygamous and monogamous matings, an observation that has been noted for Steelhead (Seamons et al. 2004a), Brown Trout (Salmo trutta, Serbezov et al. 2010), and Brook Trout (Kanno et al. 2011). In Chinook Salmon (O. tshawytscha) and Atlantic Salmon, there is evidence of polyandry but not polygyny (Bentzen et al. 2001; Fleming 1998). Theoretical expectations are that polygamy would be a common occurrence among salmonids because one sex is free of parental care (males) and intrasexual selection in the form of male-male competition is strong (de Gaudemar et al. 1998). Thus, it was not necessarily unexpected for us to observe polygamy and monogamy in Yellowstone Cutthroat Trout. From a management perspective, these findings are important as multiple paternity (or polyandry) has been shown to increase effective population size $\left(N_{\mathrm{e}}\right)$ relative to systems with strict monogamy (Pearse and Anderson 2010). It is worth noting that the parent pair-offspring relationships identified via PBT which were used to infer mating systems displayed a high level of concordance with results from sibship analysis. Our findings mirror previous efforts to resolve full-sibling families via sibship methods (Ackerman et al. 2016), and highlight that it is possible to accurately estimate sibship and $N$ b without parental genotypes (Waples and Waples 2011). The ability to infer family structure using only offspring from a single generation is significant as it can be applied in scenarios where sampling both parents and their offspring is either logistically difficult or not possible.

Another trait observed in Yellowstone Cutthroat Trout that mirrors observations from other salmonids was protandry, whereby males arrived earlier than females to spawning grounds. Although male Yellowstone Cutthroat Trout arrived earlier to spawning grounds than females (Figure 4A), the cumulative number of offspring assigned to males was highest among those that arrived midseason (Figure 4B ). Protandry has been widely documented in Pacific salmon (Morbey 2000) and Steelhead (McMillan et al. 2007, although see Seamons et al. 2004b) and it has been hypothesized that males arrive early to establish dominant access to spawning females (e.g., Healey and Prince 1998). The ability for males to establish dominance over competing males can be influenced by body size (Quinn \& Foote1994; Fleming 1998; Dickerson et al. 2002), prior residence (Foote 1990), and the ratio of sexually active females to males (e.g., operational sex ratio; OSR). Results from our generalized linear models identified both arrival date and total length as significant predictors of relative reproductive success on an individual basis. In other words, while the bulk of offspring were collectively assigned to males that arrived mid-season (Figure 4B ), early arriving males that were larger in size had the highest individual relative offspring production (Figure $\mathbf{5}$ ). There are numerous examples in the salmon literature of reproductive success being positively related to body size (e.g., Schroeder 1981; Fleming and Gross 1992; Quinn and Foote 1994; Fleming 1996; Seamons et al. 2004b; Berejikian et al. 2009; Anderson et al. 2012); however, there are other instances where the relationship is either weak, non-existent, or affected by other forms of selection (e.g., Seamons et al. 2004b; Dickerson et al. 2005; Seamons et al. 2007). Whereas different life history strategies (e.g., precocial males and jacks), behavioral strategies (e.g., sneaker or satellite males), and forms of selection (e.g., predation by terrestrial animals) may lessen the strength of the relationship between arrival time and body size on reproductive success (Dickerson et al. 2002; Dickerson et al. 2005; MacMillan et al. 2007), in our system the largest, earliest arriving males experienced the highest levels of relative reproductive success.

Pairwise genetic relatedness among adult Yellowstone Cutthroat Trout that successfully mated was not significantly different relative to adults that did not successfully reproduce, and this trend has been noted for other salmonids. Several studies have identified mate choice among salmonids, specifically at loci associated with the major histocompatibility class (MHC). In particular, both Atlantic Salmon and Chinook Salmon have been shown to select mates that increase heterozygosity at the MHC loci, but not at putatively neutral loci (Landry et al. 2001; Neff et al. 2008). Because we only surveyed Yellowstone Cutthroat Trout at putatively neutral SNP loci we were unable to test for mate association at MHC, but nonetheless, we showed 
patterns of genetic relatedness among parents supported a random mating scheme.

Lastly, we generated estimates of $N_{\mathrm{b}}$ and $N_{\mathrm{e}}$ and showed that the $N_{\mathrm{b}} / N_{\mathrm{e}}$ was less than one for Yellowstone Cutthroat Trout. Ratios of $N_{\mathrm{b}} / N_{\mathrm{e}}$ vary across freshwater fish (Brown Trout: 0.48, Lake Trout, Salvelinus namaycush : 1.212, Razorback Sucker, Xyrauchen texanus : 1.004) and simple life history characteristics such as age at maturity and adult lifespan have been shown to explain up to $2 / 3$ of the variation in observed $N$ b/ $N$ e ratios (Waples et al. 2013). In the case of Yellowstone Cutthroat Trout in the South Fork Snake River, there are two pools of potential parents capable of contributing to annual reproduction: tributary residents and mainstem adults that perform fluvial spawning migrations (Thurow et al. 1988). That we observed $N_{\mathrm{b}} / N_{\text {e }}$ ratios less than one could be explained by only a subset of the potential parent population contributing to reproduction (i.e., reduced resident or fluvial contributions), an unusually large variance in reproductive success, or a highly skewed operational sex ratio that occurred in 2016 relative to other spawn years. Because we only have data for a singular spawn year it is difficult to identify specific mechanisms to explain our observed $N_{\mathrm{b}} / N_{\text {e }}$ ratio, but nonetheless, both these values are sufficiently high to suggest that Yellowstone Cutthroat Trout in Burns Creek represent a genetically stable and diverse population.

In conclusion, we have described the mating systems of a species of conservation concern and identified important predictors of relative reproductive success. Moving forward, these data can serve as a baseline for future monitoring efforts and a template for investigations into the reproductive ecology of other freshwater salmonids. Additionally, the observation that the largest adults were responsible for producing a disproportionate amount of offspring may serve as a basis for angling restrictions. For example, Gwinn et al. (2015) identified that protection of the largest adults in the population via harvest slots (i.e., harvest is restricted to fish of intermediate length) consistently produced greater numbers of fish harvested and greater catches of trophy fish while conserving reproductive biomass and a more natural population age-structure. Throughout much of their range in Idaho (including the South Fork Snake River and its tributaries), the harvest of Yellowstone Cutthroat Trout is prohibited, but in areas where harvest is still allowed or is being considered, data generated here may be of direct relevance.

\section{ACKNOWLEDGEMENTS}

We thank Kelly Heindel, Amanda Boone and Lynn Schrader at the Idaho Department of Fish and Game Eagle Fish Genetics Lab for their assistance with processing samples. We thank Kevin Meyer and Jeff Dillon for comments that improved the quality of this manuscript. Funding for sample collection and genetic analysis was provided by the IDFG through the Federal Aid in Sport Fish Restoration Act and by Idaho anglers via license fees.

\section{CONFLICT OF INTEREST}

The authors report no conflict of interest.

\section{DATA AVAILABILITY STATEMENT}

Files containing genotype data used to characterize mating systems will be publicly available on FishGen.net at the time of publication.

\section{REFERENCES}

Anderson, E.C. 2010. Computational algorithms and user-friendly software for parentage-based tagging of Pacific salmonids. Final report submitted to the Pacific Salmon Commission's Chinook Technical Committee (US Section). 46 p.

Anderson, E.C., and Garza, J.C. 2005. A description of full parental genotyping. Technical Report, Pacific Salmon Commission.

Anderson, J.H., Faulds, P.L., Atlas, W.I. and Quinn, T.P., 2013. Reproductive success of captively bred and naturally spawned Chinook salmon colonizing newly accessible habitat. Evolutionary Applications , 6 (2), pp.165-179. 
Behnke, R. J. 1992. Native trout of western North America. American Fisheries Society, Monograph 6, Bethesda, Maryland.

Bentzen, P., Olsen, J.B., McLean, J.E., Seamons, T.R. and Quinn, T.P., 2001. Kinship analysis of Pacific salmon: insights into mating, homing, and timing of reproduction. Journal of Heredity, 92(2), pp.127-136.

Berejikian, B.A., Van Doornik, D.M., Scheurer, J.A. and Bush, R., 2009. Reproductive behavior and relative reproductive success of natural-and hatchery-origin Hood Canal summer chum salmon (Oncorhynchus keta ). Canadian Journal of Fisheries and Aquatic Sciences, 66(5), pp.781-789.

Burnham, K.P. and Anderson, D.R., 2002. A practical information-theoretic approach. Model selection and multimodel inference, 2nd ed. Springer, New York, 2.

Campbell, N.R., Harmon, S.A. and Narum, S.R., 2015. Genotyping-in-Thousands by sequencing (GT-seq): A cost effective SNP genotyping method based on custom amplicon sequencing. Molecular ecology resources, 15(4), pp.855-867.

Charlesworth, B., 2009. Effective population size and patterns of molecular evolution and variation. Nature Reviews Genetics, 10(3), pp.195-205.

De Gaudemar, B., 1998. Sexual selection and breeding patterns: insights from salmonids (Salmonidae). Acta Biotheoretica, 46(3), pp.235-251.

DeWoody, J.A. and Avise, J.C., 2001. Genetic perspectives on the natural history of fish mating systems. Journal of Heredity, 92(2), pp.167-172.

Dickerson, B.R., Quinn, T.P. and Willson, M.F., 2002. Body size, arrival date, and reproductive success of pink salmon, Oncorhynchus gorbuscha . Ethology Ecology \& Evolution, 14(1), pp.29-44.

Dickerson, B.R., Brinck, K.W., Willson, M.F., Bentzen, P. and Quinn, T.P., 2005. Relative importance of salmon body size and arrival time at breeding grounds to reproductive success. Ecology, 86(2), pp.347-352.

Esteve, M., 2005. Observations of spawning behaviour in Salmoninae:Salmo, Oncorhynchus and Salvelinus . Reviews in Fish Biology and Fisheries, 15(1-2), pp.1-21.

Fleming, I.A., 1996. Reproductive strategies of Atlantic salmon: ecology and evolution. Reviews in Fish Biology and Fisheries, 6(4), pp.379-416.

Fleming, I.A., 1998. Pattern and variability in the breeding system of Atlantic salmon (Salmo salar), with comparisons to other salmonids. Canadian journal of fisheries and aquatic sciences, 55(S1), pp.59-76.

Fleming, I.A. and Gross, M.R., 1992. Reproductive behavior of hatchery and wild coho salmon (Oncorhynchus kisutch ): does it differ? Aquaculture, 103(2), pp.101-121.

Foote, C.J., 1990. An experimental comparison of male and female spawning territoriality in a Pacific salmon. Behaviour, 115(3-4), pp.283-314.

Frankham, R., 2005. Genetics and extinction. Biological conservation, 126(2), pp.131-140.

Garant, D., Dodson, J.J. and Bernatchez, L., 2001. A genetic evaluation of mating system and determinants of individual reproductive success in Atlantic salmon (Salmo salar L.). Journal of Heredity, 92(2), pp.137145 .

Gustafson, R.G., Waples, R.S., Myers, J.M., Weitkamp, L.A., Bryant, G.J., Johnson, O.W. and Hard, J.J., 2007. Pacific salmon extinctions: quantifying lost and remaining diversity. Conservation Biology, 21(4), pp.1009-1020.

Gwinn, D.C., Allen, M.S., Johnston, F.D., Brown, P., Todd, C.R. and Arlinghaus, R., 2015. Rethinking length-based fisheries regulations: the value of protecting old and large fish with harvest slots. Fish and Fisheries, 16(2), pp.259-281. 
Healey, M.C., and Prince, A., 1998. Alternative tactics in the breeding behaviour of male coho salmon. Behaviour, 135(8), pp.1099-1124.

Idaho Department of Fish and Game (IDFG). 2007. Management plan for conservation of Yellowstone Cutthroat Trout in Idaho. Agency Report. Boise, Idaho. 110pp

Jones, O.R. and Wang, J., 2010. COLONY: a program for parentage and sibship inference from multilocus genotype data. Molecular Ecology Resources, 10(3), pp.551-555.

Kanno, Y., Vokoun, J.C. and Letcher, B.H., 2011. Sibship reconstruction for inferring mating systems, dispersal and effective population size in headwater brook trout (Salvelinus fontinalis ) populations. Conservation Genetics, 12(3), pp.619-628.

Kruse, C.G., Hubert, W.A. and Rahel, F.J., 2000. Status of Yellowstone cutthroat trout in Wyoming waters. North American Journal of Fisheries Management, 20(3), pp.693-705.

Landry, C. and Bernatchez, L., 2001. Comparative analysis of population structure across environments and geographical scales at major histocompatibility complex and microsatellite loci in Atlantic salmon (Salmo salar ). Molecular Ecology, 10(10), pp.2525-2539.

Lepais, O., Darvill, B.E.N., O'connor, S., Osborne, J.L., Sanderson, R.A., Cussans, J., Goffe, L. and Goulson, D., 2010. Estimation of bumblebee queen dispersal distances using sibship reconstruction method. Molecular Ecology, 19(4), pp.819-831.

Li, C.C., Weeks, D.E. and Chakravarti, A., 1993. Similarity of DNA fingerprints due to chance and relatedness. Human Heredity, 43(1), pp.45-52.

Lynch, M. and Ritland, K., 1999. Estimation of pairwise relatedness with molecular markers. Genetics, 152(4), pp.1753-1766.

May, B. E., W. Urie, and B. B. Shepard. 2003. Rangewide status of Yellowstone cutthroat trout (Oncorhynchus clarki bouvieri ): 2001. Yellowstone Cutthroat Trout Interagency Coordination Group, Bozeman, Montana.

McElhany, P., Ruckelshaus, M.H., Ford, M.J., Wainwright, T.C., and Bjorkstedt, E.P. 2000. Viable populations and the recovery of evolutionary significant units. NOAA Technical Memorandum NMFS-NWFSC 42, $156 \mathrm{pp}$.

McMillan, J.R., Katz, S.L. and Pess, G.R., 2007. Observational evidence of spatial and temporal structure in a sympatric anadromous (winter steelhead) and resident rainbow trout mating system on the Olympic Peninsula, Washington. Transactions of the American Fisheries Society, 136(3), pp.736-748.

Meyer, K.A., Schill, D.J., Elle, F.S. and Schrader, W.C., 2003. A long-term comparison of Yellowstone cutthroat trout abundance and size structure in their historical range in Idaho. North American Journal of Fisheries Management, 23(1), pp.149-162.

Meyer, K.A., Schill, D.J., Lamansky Jr, J.A., Campbell, M.R. and Kozfkay, C.C., 2006. Status of Yellowstone cutthroat trout in Idaho. Transactions of the American Fisheries Society, 135(5), pp.1329-1347.

Meyer, K.A., Larson, E. I., Sullivan, C. L., High, B., 2014. Trends in the Distribution and Abundance of Yellowstone Cutthroat Trout and Nonnative Trout in Idaho. Journal of Fish and Wildlife Management, 5(2), pp. 227-242.

Moore, V. and Schill, D., 1984. South Fork Snake River fisheries investigations. Idaho Department of Fish and Game, Job Completion Report. Project F-73-R-5, Boise.

Morbey, Y., 2000. Protandry in Pacific salmon. Canadian Journal of Fisheries and Aquatic Sciences, 57(6), pp.1252-1257. 
Neff, B.D., Garner, S.R., Heath, J.W. and Heath, D.D., 2008. The MHC and non-random mating in a captive population of Chinook salmon. Heredity, 101(2), pp.175-185.

Pearse, D.E. and Anderson, E.C., 2009. Multiple paternity increases effective population size. Molecular Ecology, 18(15), pp.3124-3127.

Pew, J., Muir, P.H., Wang, J. and Frasier, T.R., 2015. related: an R package for analysing pairwise relatedness from codominant molecular markers. Molecular Ecology Resources, 15(3), pp.557-561.

Queller, D.C. and Goodnight, K.F., 1989. Estimating relatedness using genetic markers. Evolution, 43(2), pp.258-275.

Quinn, T.P. and Foote, C.J., 1994. The effects of body size and sexual dimorphism on the reproductive behaviour of sockeye salmon, Oncorhynchus nerka . Animal Behaviour, 48(4), pp.751-761.

R Core Team. 2020. R: A language and environment for statistical computing. R Foundation for Statistical Computing, Vienna, Austria. http://www.r-project.org/index.html

Roth, C.J., Schill, D.J., Quist, M.C. and High, B., 2018. Effects of air exposure in summer on the survival of caught-and-released salmonids. North American Journal of Fisheries Management, 38(4), pp.886-895.

Schill, D.J., Heindel, J.A., Campbell, M.R., Meyer, K.A. and Mamer, E.R., 2016. Production of a YY male brook trout broodstock for potential eradication of undesired brook trout populations. North American Journal of Aquaculture, 78(1), pp.72-83.

Schroder, S.L. 1981 the role of sexual selection in determining overall mating patterns and mate choice in chum salmon. PhD. Dissertation, Univ. of Washington. Seattle, 274p

Seamons, T.R., Bentzen, P. and Quinn, T.P., 2004a. The mating system of steelhead, Oncorhynchus mykiss , inferred by molecular analysis of parents and progeny. Environmental Biology of Fishes, 69, pp. 333-344.

Seamons, T.R., Bentzen, P. and Quinn, T.P., 2004b. The effects of adult length and arrival date on individual reproductive success in wild steelhead trout (Oncorhynchus mykiss). Canadian Journal of Fisheries and Aquatic Sciences, 61(2), pp.193-204.

Seamons, T.R., Bentzen, P. and Quinn, T.P., 2007. DNA parentage analysis reveals inter-annual variation in selection: results from 19 consecutive brood years in steelhead trout. Evolutionary Ecology Research, 9(3), pp.409-431.

Serbezov, D., Bernatchez, L., Olsen, E.M. and Vøllestad, L.A., 2010. Mating patterns and determinants of individual reproductive success in brown trout (Salmo trutta) revealed by parentage analysis of an entire stream living population. Molecular Ecology, 19(15), pp.3193-3205.

Steele, C.A., Anderson, E.C., Ackerman, M.W., Hess, M.A., Campbell, N.R., Narum, S.R. and Campbell, M.R., 2013. A validation of parentage-based tagging using hatchery steelhead in the Snake River basin. Canadian Journal of Fisheries and Aquatic Sciences, 70(7), pp.1046-1054.

Steele, C.A., Hess, M., Narum, S. and Campbell, M., 2019. Parentage-based tagging: Reviewing the implementation of a new tool for an old problem. Fisheries, 44(9), pp.412-422.

Thurow, R.F., Corsi, C.E. and Moore, V.K., 1988. Status, ecology, and management of Yellowstone cutthroat trout in the upper Snake River drainage, Idaho. In: Status and Management of Interior Stocks of Cutthroat Trout. Eds. R.E. Gresswell. American Fisheries Society, Symposium Vol. 4, pp. 25-36.

Varley, J.D. and Gresswell, R.E., 1988. Ecology, status, and management of the Yellowstone cutthroat trout. In: Status and Management of Interior Stocks of Cutthroat Trout. Eds. R.E. Gresswell. American Fisheries Society, Symposium. Vol. 4, pp. 13-24.

Venables, W.N. and Ripley, B.D., 2002. Random and mixed effects. In Modern applied statistics with S (pp. 271-300). Springer, New York, NY. 
Wang, J., 2007. Parentage and sibship exclusions: higher statistical power with more family members. Heredity, 99(2), pp.205-217.

Waples R.S. (2002) Definition and estimation of effective population size in the conservation of endangered species. In: Population Viability Analysis (ed. by S.R. Beissinger \& D.R. McCullough), pp. 147-168. The University of Chicago Press, Chicago, IL, USA.

Waples, R. S., \& Waples, R. K. (2011) Inbreeding effective population size and parentage analysis without parents. Molecular Ecology Resources, 11, 162-171.

Waples, R.S., Luikart, G., Faulkner, J.R. and Tallmon, D.A., 2013. Simple life-history traits explain key effective population size ratios across diverse taxa. Proceedings of the Royal Society B: Biological Sciences, 280(1768), p.20131339.

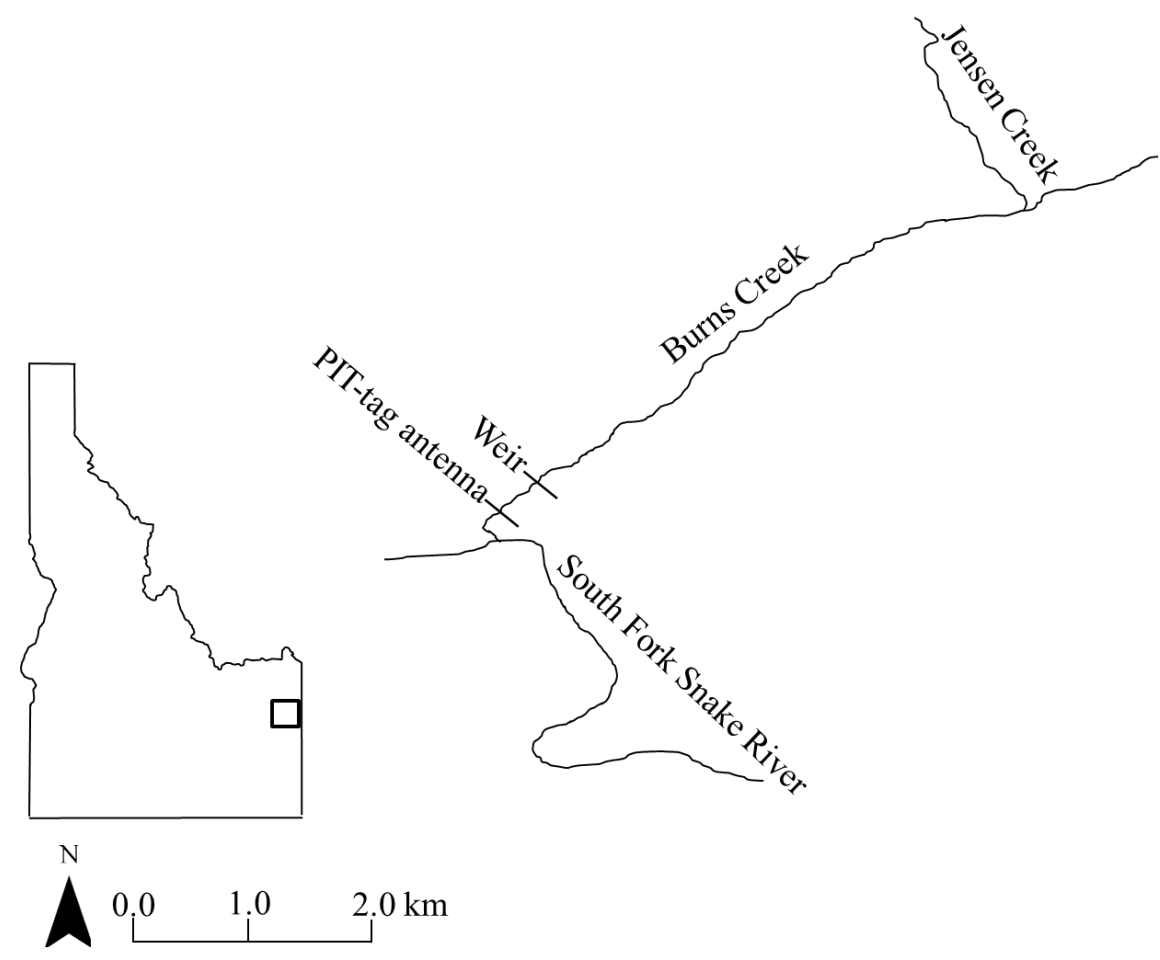

Figure 1. A map of Burns Creek, a tributary to the South Fork Snake River in Idaho. Marked on Burns Creek is the placement of the adult weir where upstream migrating Yellowstone Cutthroat Trout (Oncorhynchus clarkii bouvieri) were sampled for genetics. 

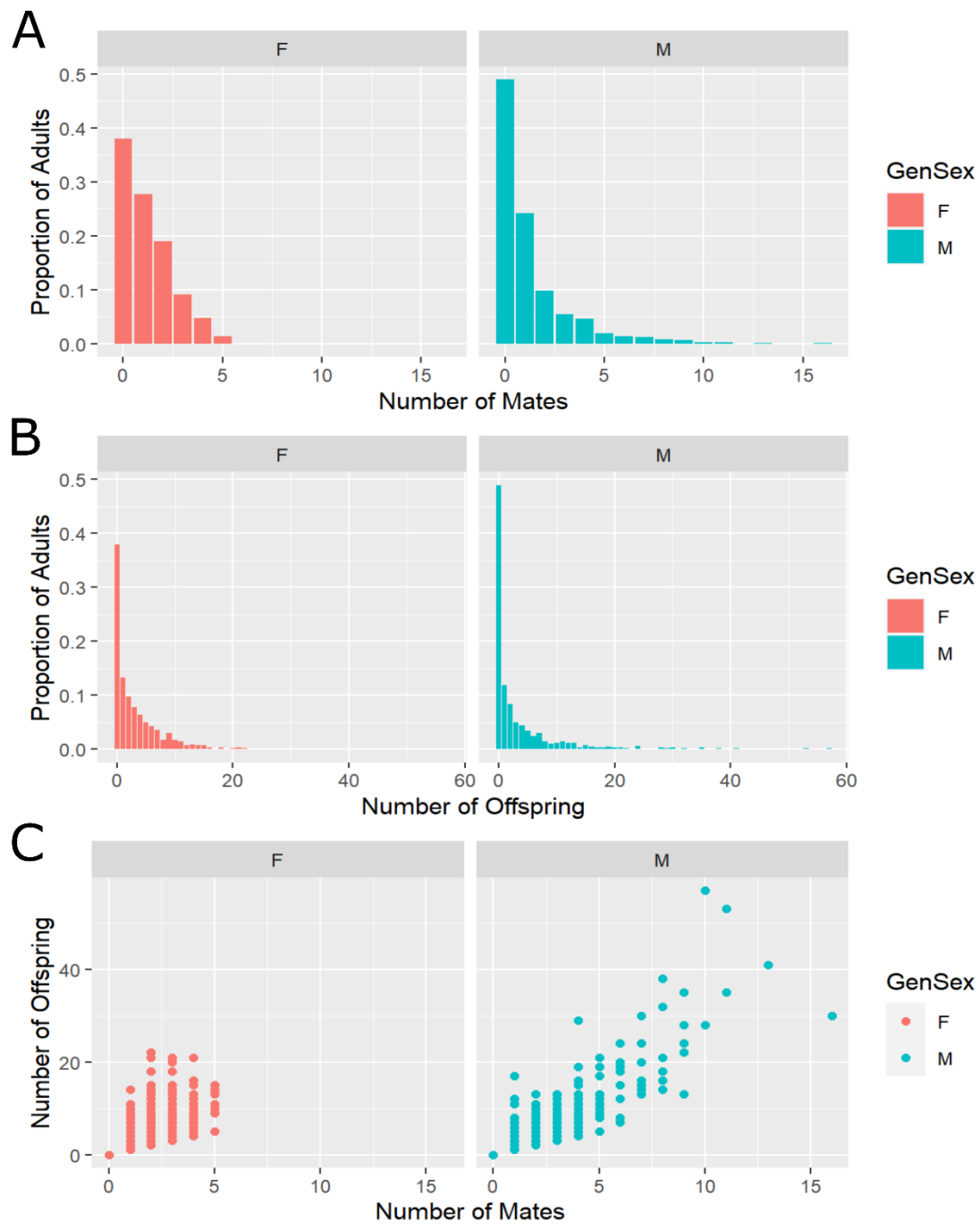

Figure 2 . A) A histogram of the number of mates acquired by female and male Yellowstone Cutthroat Trout (YCT) from Burns Creek, Idaho during the 2016 spawning season. B) A histogram showing the distribution of relative reproductive success as measured by the number of offspring assigned to each adult by sex. C) A plot showing the relationship between the numbers of mates per adult versus the number of offspring assigned to the same individual. 

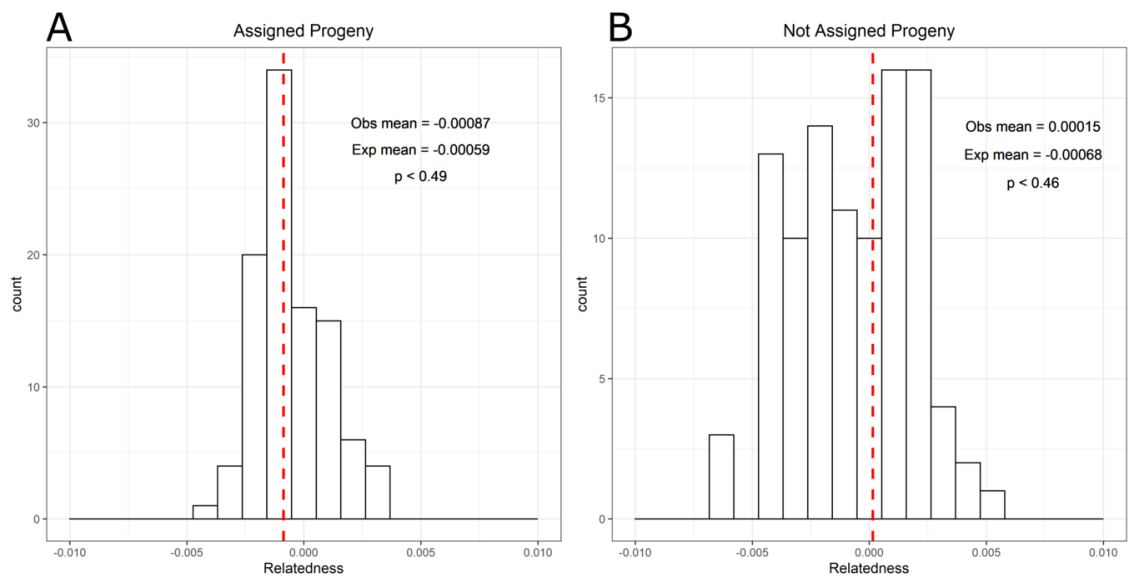

Figure 3. A histogram displaying expected values of relatedness $\left(R_{\mathrm{xy}}\right)$ among groups of adult Yellowstone Cutthroat trout; (A ) adults assigned progeny via parentage analysis, and (B ) adults without any assigned progeny. Vertical dotted lines correspond to the observed mean levels of relatedness among individuals within a group (Obs mean) and mean expected values of relatedness (Exp mean) generated by randomly shuffling individuals between groups are listed in the upper right of each graph. P-values represent the number of simulations out of the total number ran that were less than or equal to our observed value.
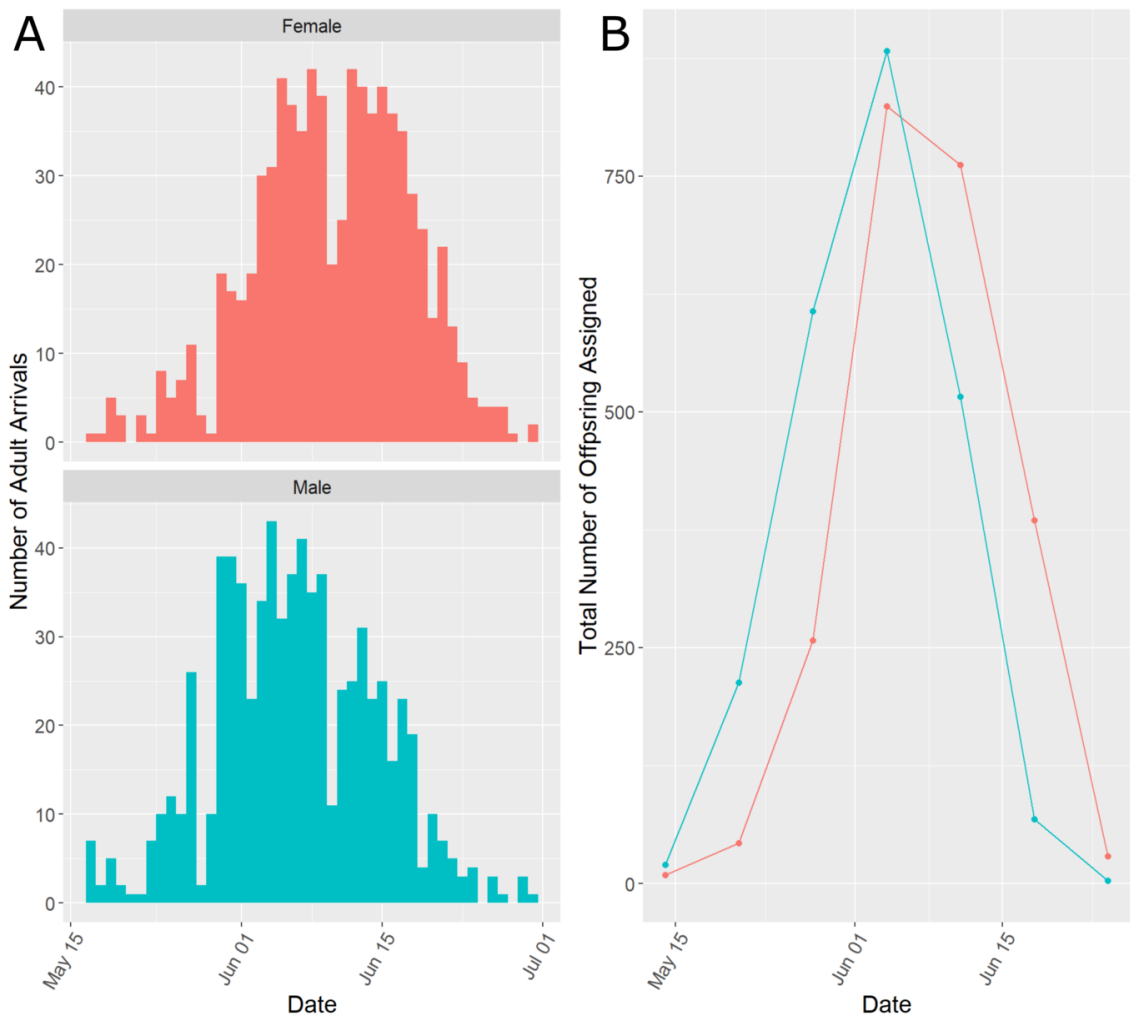

Figure 4. The number of adult Yellowstone Cutthroat Trout sampled at an instream weir on Burns Creek, Idaho en route to spawning grounds as a function of date (A ). The total number of offspring assignments as a function of adult arrival date grouped by week is presented in panel $\mathbf{B}$. 

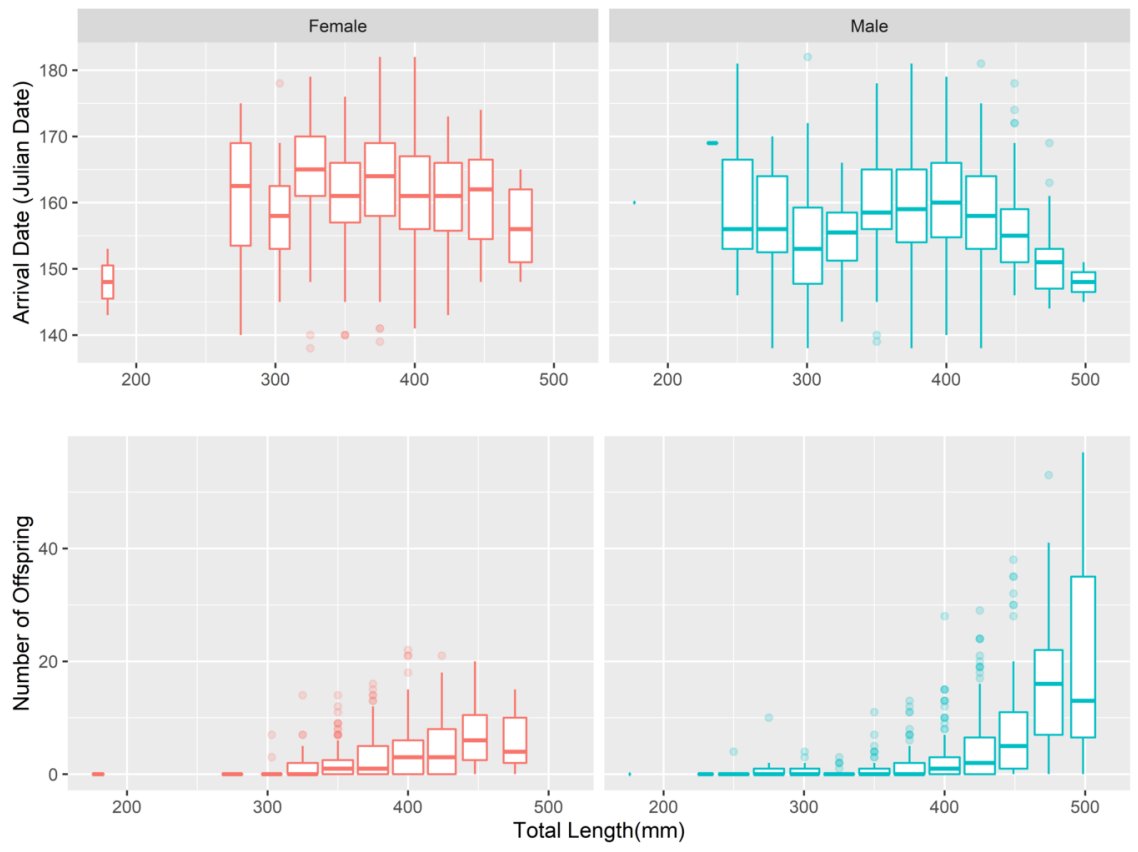

Figure 5. The Julian date adult Yellowstone Cutthroat Trout were handled at an instream weir as a function of length in Burns Creek, Idaho (Top ). Fish with smaller Julian dates correspond to those that arrived earlier. Also presented is the number of offspring produced per adult as a function of total length $(\mathrm{mm})$ (Bottom ). For both sets of plots, the lower and upper hinges of rectangles correspond to the first and third quartiles (the 25th and 75th percentiles) and bars represent median values. The upper and lower whisker extend from the hinge to the largest value no further than $1.5 \mathrm{x}$ the interquartile range. Data beyond the end of whiskers represent outliers.

Table 1. Outputs from generalized linear models which sought to explain the relative predictive importance of total length and arrival time at the spawning ground on relative reproductive success of Yellowstone Cutthroat Trout in Burns Creek, Idaho. Two suites of models were run, one each for male and female adults. Parameters are as follows: Length $=$ total length $(\mathrm{mm})$, Date $=$ Julian date of arrival at an instream weir which was directly downstream from spawning habitats. $K=$ number of model parameters, AICc $=$ Akaike information criteria corrected for small sample size, [?]AICc $=$ difference between each model and the best performing model, and $w_{\mathrm{i}}=$ the Akaike weight.

\begin{tabular}{llllll}
\hline Sex & Model & K & AICc & {$[?] \mathbf{A I C}$} & $w_{\mathbf{i}}$ \\
\hline Female & Length + Date & 5 & 3367.1 & - & 0.796 \\
& Length + Date + Length*Date & 7 & 3370.0 & 2.8 & 0.194 \\
& Length & 3 & 3375.8 & 8.6 & 0.011 \\
& Date & 4 & 3426.8 & 59.7 & 0 \\
& nullmodel & 2 & 3434.3 & 67.2 & 0 \\
Male & Length + Date & 5 & 2842.2 & - & 0.858 \\
& Length + Date + Length*Date & 7 & 2845.8 & 3.6 & 0.142 \\
& Length & 3 & 2859.8 & 17.6 & 0 \\
& Date & 4 & 2991.3 & 149.1 & 0 \\
& nullmodel & 2 & 3017.3 & 175.1 & 0 \\
\hline
\end{tabular}

